There was, however, relative confidence with regard to immunisations, 6 week checks, heart murmurs, and other medical and surgical problems, which were perhaps well covered by vocational training.

\section{Discussion}

This study was done in a deprived inner city area where previous training and experience in paediatric surveillance has been low compared with other parts of the country. ${ }^{6}$ The high response rate suggests enthusiasm towards child health surveillance and an eagerness for appropriate training. General practitioners were fairly clear about the areas in which they wanted more training and opinion tended to be consistent.

As general practitioners perform more paediatric surveillance the health authority role may change, with training and advice for general practitioners becoming as important as providing clinical services. While theoretical courses can readily be tailored to address gaps in knowledge, the high demand for practical training has implications for community services. Speech therapy and audiology departments, district handicap teams, child guidance and social services could all provide training on an individual or small group basis.

The fact that so many doctors gain their experience of child health surveillance within general practice suggests that the training role of these general practice clinics should be recognised and enhanced. This could be achieved through regular support from senior community paediatricians, perhaps visiting and contributing to after clinic meetings.

The key to a successful child health programme lies in the relationship between doctors, health visitors, and others in the community health services. Multidisciplinary refresher training is one way to strengthen these links at the grass roots but such courses must address specific needs. Although this survey provides information about the topics general practitioners would wish to cover, it would be helpful to have the same information from the other professionals.

1 Committee on Child Health Services. Fit for the future. London: HMSO, 1976:448. (Court report.) (Cmmd 6680.) 2 Donald AG, chairman. The care of children-college policy. I R Coll Gen Pract 1978;28:553-6.

3 Marsh GN, Russell D, Russell I. Is paediatrics safe in general practitioners' hands? A study in the north of England. $\mathcal{F} R$ Coll Gen Pract 1989;39:138-41.

4 Wilmot JF. Preparation for paediatric surveillance. A survey of trainee general practitioners. The Practitioner 1984;228: 975-7.

5 Horder JP, chairman. The paediatrics training required in the general practitioner. $\mathcal{f} R$ Coll Gen Pract 1976;26: the gen

6 Burke P, Bain J. Paediatric developmental screening: a survey of general practitioners. $\mathcal{F} R$ Coll Gen Pract 1986; 36:302-6.

\title{
Haem arginate in acute hereditary coproporphyria
}

\author{
D J Manning, T A Gray
}

\begin{abstract}
An 11 year old boy presented with severe acute hereditary coproporphyria. Despite supportive measures his condition deteriorated after admission. Haem arginate, started two days after presentation, produced appreciable inhibition of porphyrin precursor overproduction and clinical improvement.
\end{abstract}

Hereditary coproporphyria is the least common of the hepatic porphyrias. About $35 \%$ of cases present acutely. ' Recently haem arginate, a stable haem compound, has been shown to reduce porphyrin precursor overproduction during acute attacks. ${ }^{2}$ We report its use during severe acute hereditary coproporphyria.

\section{Case report}

An 11 year old boy was admitted after a generalised seizure. He was vomiting for nine days despite prochlorperazine and metoclopramide, and had lethargy, abdominal pain, and constipation for four days. He had eaten little in the week before admission. Apart from constipation he was previously well. His father, aged
44, had mild hypertension. Otherwise there was no significant family history.

On examination he was agitated and confused, but localising pain appropriately. Axillary temperature was $36.5^{\circ} \mathrm{C}$. The pupils were dilated but reactive, and there was no papilloedema. The ankle jerks were brisk, with clonus, and the plantar responses were equivocal. The pulse rate was $160 /$ minute and blood pressure $150 / 110 \mathrm{~mm} \mathrm{Hg}$. The precordial impulse was hyperdynamic. The respiratory rate was $16 /$ minute with shallow breaths. Abdominal examination was normal.

Investigations showed a normal peripheral white cell count and differential. Plasma urea concentration was $10 \mathrm{mmol} / 1$, glucose $9 \cdot 7 \mathrm{mmol}$ 1 , and electrolytes were normal. There was mixed respiratory and metabolic acidosis with arterial $\mathrm{pH} 7 \cdot 083$, carbon dioxide tension $8 \cdot 27$ $\mathrm{kPa}$, oxygen tension $14.4 \mathrm{kPa}$, and base excess $-12 \cdot 9$. Computed tomography of the brain was normal, and lumbar puncture showed normal cerebrospinal fluid.

Seizures persisted despite intravenous diazepam and he was given a single loading dose of intravenous phenytoin followed by a clonazepam infusion. Hypertension and tachycardia 
Urine porphyrin precursors before, during, and after treatment with haem arginate. Day 0 is the day of presentation

\begin{tabular}{llc}
\hline Day & $\begin{array}{l}\text { DALA } \\
(\mu \mathrm{mol} / \mathrm{l}) t\end{array}$ & $\begin{array}{l}\text { Porphobilinogen } \\
(\mu \mathrm{mol} / \mathrm{l}) t\end{array}$ \\
\hline 0 & $758 \cdot 0$ & $355 \cdot 0$ \\
1 & & \\
$2^{*}$ & & \\
$3^{*}$ & $25 \cdot 6$ & $20 \cdot 2$ \\
$4^{*}$ & $24 \cdot 7$ & $\mathrm{ND}$ \\
$5^{*}$ & 21.0 & $4 \cdot 7$ \\
6 & $42 \cdot 1$ & $5 \cdot 1$ \\
7 & 13.7 & $3 \cdot 1$ \\
8 & & \\
\hline
\end{tabular}

${ }^{*}$ Indicates days on which haem arginate $(100 \mathrm{mg})$ was given †Reference ranges: DALA, $0 \cdot 8-34 \cdot 3 \mu \mathrm{mol} / \mathrm{l}$; porphobilinogen,
$0-8 \cdot 8 \mu \mathrm{mol} / \mathrm{l}$.

persisted, and there was progressive diminution in level of consciousness, accompanied by dystonic posturing and loss of the gag reflex. This deterioration continued despite stopping the clonazepam. Serum sodium concentration fell from 134 to $124 \mathrm{mmol} / \mathrm{l}$ with a urine sodium of $131 \mathrm{mmol} / \mathrm{l}$. Urine osmolality was $940 \mathrm{mosm} / \mathrm{kg}$ compared with serum osmolality $245 \mathrm{mosm} / \mathrm{kg}$, consistent with inappropriate antidiuretic hormone secretion. Urine studies showed massively raised porphyrin precursors (table). Supportive treatment consisted of intravenous dextrose, ventilation, fluid restriction, and demeclocycline. In order to inhibit porphyrin precursor overproduction, haem arginate was started two days after admission.

There was gradual clinical improvement during the next three days, and blood pressure and pulse returned to normal. Improvement began three days after the phenytoin and 1.5 days after clonazepam was stopped. No further seizures occurred and he was successfully weaned from ventilation on the fourth day of treatment with haem arginate. There was a dramatic fall in porphyrin precursor overproduction (table) and rise in serum sodium concentration to 136 $\mathrm{mmol} / \mathrm{l}$. This improvement continued after treatment with haem arginate was stopped and three weeks after admission he was clinically normal.

Faecal coproporphyrins were raised to 320 (normally up to 46) nmol/g dry weight. EpsteinBarr virus transformed lymphocytes showed reduced coproporphyrinogen oxidase activity: $4.7 \mathrm{nmol}$ carbon dioxide/hour/mg protein compared with control values (range) of $8 \cdot 8(7 \cdot 4$ $10 \cdot 3$ ), indicating hereditary coproporphyria. Similar activities were found in lymphocytes from his brother and mother indicating that he was affected and she was the carrier.

\section{Discussion}

This boy presented with classic features of acute porphyria: abdominal pain, constipation, hy- pertension, encephalopathy, and inappropriate antidiuretic hormone production. Possibly phenytoin, given before the diagnosis was made, contributed to the deterioration after admission. Although hereditary coproporphyria is reputedly milder than acute intermittent porphyria, this episode was undoubtedly life threatening.

Haem production regulates, by feedback inhibition, $\delta$-amino laevulinic acid (DALA) synthase. In acute porphyria defective haem biosynthesis results in overactivity of this enzyme. Clinical features are thought to be due to consequent overproduction of porphyrin precursors, though haem deficiency may also be relevant. For these reasons treatment with haem has been advocated. Haematin, produced by dissolving haemin in alkali, was first used. Solutions of haematin are unstable, which may have contributed to clinical ineffectiveness. In addition, haematin degradation products were implicated in side effects, including thrombophlebitis and coagulation disturbances. ${ }^{3}$

Recently, haem arginate has been shown to be much more stable than haematin with stability in stock solution of $96 \%$ in two years. ${ }^{3}$ In a double blind study in 12 patients with acute intermittent porphyria, haem arginate significantly inhibited porphyrin precursor overproduction. $^{2}$ Clinical benefits were less striking, the treated group showing nonsignificant reductions in analgesic requirement, pain score, and duration of admission. The only side effect noted was mild phlebitis at the injection site in five patients. The authors suggested that the lack of statistical significance was due to the small numbers studied. They recommended that haem arginate be given to patients with severe attacks or those with peripheral neuropathy.

Porphyria commonly presents around puberty and so may present to the paediatrician. Early diagnosis and appropriate management can lead to complete remission. The most important aspects of management are removal of aggravating factors, analgesia, careful fluid balance, and intensive monitoring. For severe cases rational treatment without appreciable side effects is now available.

We thank Dr BAM Smith for permission to report this case, Professor A Goldberg for advice with managment, Dr ARW Forrest for measuring DALA and porphobilinogen, and Professor $\mathrm{G}$ Elder for measuring coproporphyringogen oxidase.

1 Brodie MJ, Thompson GG, Moore MR, Beattie AD, Goldberg A. Hereditary coproporphyria. $Q \mathcal{F}$ Med 1977 182:229-41

2 Herrick AL, McColl KEL, Moore MR, Cook A, Goldberg A. Controlled trial of haem arginate in acute hepatic porphyria. Lancet 1989;i:1295-7.

3 Tenhunen $\mathrm{R}$, Tokola $\mathrm{O}$, Linden I-B. Haem arginate: a new stable compound. F Pharm Pharmacol 1987;39:780-6. 